\title{
La Escenificación de una Mirada y el Testimonio de los Cuerpos en el Teatro Documental de Vivi Tellas
}

\author{
Pamela Brownell \\ Universidad de Buenos Aires - UBA, Buenos Aires, Argentina
}

RESUMEN - La Escenificación de una Mirada y el Testimonio de los Cuerpos en el Teatro Documental de Vivi Tellas - En este artículo recorreremos algunos enfoques teóricos para analizar la propuesta artística de la directora argentina Vivi Tellas materializada en su proyecto de teatro documental Archivos, el cual se enmarca dentro de su macro-proyecto Biodrama. Analizaremos distintas claves que definen su modo particular de trabajar con aquellos materiales reales con los que construye sus espectáculos, reflexionando sobre las posibles implicancias éticas y estéticas de este trabajo. Un lugar privilegiado tendrán en esta reflexión las ideas de Giorgio Agamben respecto principalmente de la noción de testigo, que nos permitirán acercarnos a una hipótesis sobre el tipo de testimonio que brindan los cuerpos - de personas comunes y corrientes - y también los objetos/documentos que Tellas lleva a escena.

Palabras-clave: Teatro Argentino Contemporáneo. Vivi Tellas. Teatro Documental. Biodrama. Testimonio.

ABSTRACT - The Staging of a Point of View and Testimony of the Bodies in Vivi Tellas's Documentary Theatre - In this article we review some theoretical approaches to the artistic proposal of Argentine theatre director Vivi Tellas, focusing on her documentary theatre project Archivos, an expression of her wider project Biodrama. We will look into different aspects that define her particular way of working with the real materials her performances are based on, and we will consider the possible ethical and aesthetic implications of her work. Giorgio Agamben's notion of witness will play a special role in this analysis, since it enables us to formulate a hypothesis about the kind of testimony given by these ordinary bodies as well as by the objects/documents Tellas brings to the stage.

Keywords: Contemporary Argentine Theatre. Vivi Tellas. Documentary Theatre. Biodrama. Testimony.

RÉSUMÉ - La Mise en Scène d'un Regard et le Témoignage des Corps dans le Théâtre Documentaire de Vivi Tellas - Dans cet article nous parcourrons quelques perspectives théoriques pour analyser la proposition artistique de la metteuse en scène argentine Vivi Tellas, matérialisée dans son projet de théâtre documentaire Archivos, qui fait partie de son macro-projet Biodrama. Nous analyserons les clés distinctives qui définissent sa manière particulière de travailler avec ces "matériels réels" avec lesquels elle construit ses spectacles, en réfléchissant aux possibles implications éthiques et esthétiques de ce travail. Les idées de Giorgio Agamben autour de la notion de témoin seront très importantes pour cette réflexion, puisqu'elles nous permettront de formuler une hypothèse sur le type de témoignage qu'offrent les corps ordinaires et les objets/documents que Tellas porte à la scène.

Mots-clés: Théâtre Argentin Contemporain. Vivi Tellas. Théâtre Documentaire. Biodrama. Témoignage. 
Yo no quiero que la gente vea el cuadro, sino que se dé cuenta de que tiene un ojo-ser que debe usar, no para mirar los cuadros, sino para mirar el mundo, para mirarnos los unos a los otros y para conocernos a nosotros mismos. Esto, con el propósito de darnos cuenta de que, lo mismo que un árbol vive para hacer un fruto, nosotros vivimos para realizar un ser humano y ésa es la razón de nuestra vida... Por eso digo que no soy pintor sino artista. El artista tiene la función de dar a ver, tiene que mostrar lo que no se ve en la vida diaria, para así darnos una representación de dónde estamos (Matta, 1975, s/p) ${ }^{1}$.

Aquello que Matta se plantea como deber y querer para su arte está en el centro mismo de la problemática del teatro actual a la que deseo aproximarme en este trabajo: las implicancias del ver y el dara-ver, de una mirada señalada y escenificada, y de llevar adelante un intento estético que propone probar en el arte modos de ser en el mundo.

El objeto particular de estudio que constituye alternativamente la figura y el fondo de este trabajo es el Proyecto Archivos, de la directora argentina Vivi Tellas, al que ella misma identifica como teatro documental. El mismo está comprendido dentro su programa estético de la última década denominado Biodrama y que, básicamente, se propone experimentar formas escénicas para las biografías. Este término ha alcanzado una gran difusión en la escena argentina y puede encontrárselo muchas veces utilizado como si se tratara de un género.

Dentro del contexto amplio de experiencias que Tellas ha llevado adelante en el marco de Biodrama, Archivos incluye específicamente una cantidad de espectáculos bajo su dirección que tienen muchos rasgos comunes. El proyecto ha incluido hasta el momento nueve obras: Mi mamá y mi tía (2003), Tres filósofos con bigotes (2004/reestreno 2008), Cozarinsky y su médico (2005), Escuela de conducción (2006), Disc Jockey (2008), Mujeres Guí (2008/reestreno 2011), Rabbi Rabino (2011), O rabino e seu filho (2012) y La bruja y su hija (2012). La mayoría de ellas fue estrenada en Buenos Aires, mientras que Rabbi Rabino se realizó en Nueva York y $O$ rabino e seu filho, en San Pablo. Aunque las reflexiones de este trabajo toman en consideración la totalidad del proyecto, aquí me centraré en Mujeres Guia como ejemplo concreto, ya que es la obra que - por haber integrado el equipo de producción para su reestreno - conozco de un modo más cercano. 


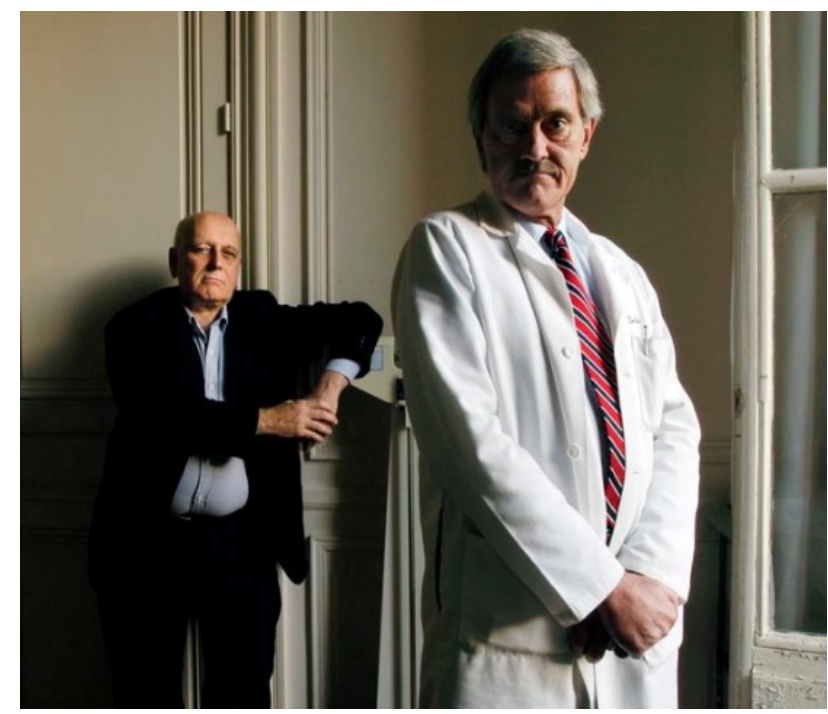

Imagen 1 - Edgardo Cozarinsky y Alejo Florín, Cozarinsky y su médico, 2005, dirección de Vivi Tellas, Buenos Aires, Argentina, Imagen de difusión. Fotografía: Nicolás Goldberg.

En líneas generales, y como los mismos títulos de las obras ayudan a suponer, la particularidad fundamental de este trabajo es que invita a escena a personas reales, cuyo oficio no es la actuación. En base a sus historias propone, desde una dramaturgia muy personal, un esquema de cuadros que permiten al espectador acercarse a ciertos aspectos de esos mundos. A algunas anécdotas, algunos temas, algunas sensaciones.

En este artículo me propongo analizar distintas claves que definen el modo particular de trabajar de Tellas con aquellos "materiales reales" con los que construye sus espectáculos. Considero que la propuesta de esta artista se inserta de lleno en las discusiones más vitales del arte contemporáneo y que su modo de interactuar con el mundo que la rodea constituye en sí mismo un manifiesto sobre un lugar deseable para el arte en nuestra sociedad y sobre las posibilidades específicas del teatro y sus cuerpos en escena para re-entramar lazos disueltos en la comunidad. Me interesará abordar este proyecto a partir de estas ideas sobre su relevancia estético-política, teniendo en cuenta algunos de los efectos que puede generar en los espectadores $\mathrm{y}$ algunos de sus procedimientos constructivos.

Un lugar privilegiado tendrán en esta reflexión las ideas de Giorgio Agamben (2002) respecto principalmente de la noción de testigo, que nos permitirán acercarnos a una hipótesis sobre el tipo de testimonio que brindan los cuerpos - de personas comunes y corrientes - y también los objetos/documentos que Tellas lleva a escena. En el plano de los efectos, analizaremos el potencial multiplicador 
que surge de la identificación provocada por la lógica del muestreo subyacente en esta forma de teatro documental, que se apoya sobre todo en lo que Michel de Certau (1980) llamaría las artes de hacer de estas personas. Por último, en un tercer apartado nos dedicaremos a la dinámica de la puesta en escena de Archivos, caracterizada por una tensión permanente entre autenticidad y artificio, realidad y teatro, buscando sintetizar algunas claves de la estrategia artística y de la poética de dirección de Tellas.

Para concluir una primera semblanza general del proyecto, quisiera señalar algunos de esos rasgos estructurales comunes que comparten las obras de Archivos: a) que el ingreso del público siempre se produce cuando los intérpretes (ésa es la denominación que Tellas prefiere para ellos) ya se encuentran realizando alguna acción en escena; b) que en un costado se encuentra siempre una "mesa de trabajo" en la que se apoyan todos los documentos que se irán mostrando a lo largo de la función; c) que la articulación de las intervenciones está siempre organizada como una secuencia de estaciones-episodios que los intérpretes van atravesando y en las que los momentos más autobiográficos y confesionales se articulan con otros propiamente performáticos, como un momento de baile o la representación actuada de alguna escena referida y, por último; d) que todas terminan con una picada temática, es decir una comida informal vinculada de algún modo al mundo de la obra, en la que los intérpretes y el público se mezclan y pueden - si así lo desean - dialogar.

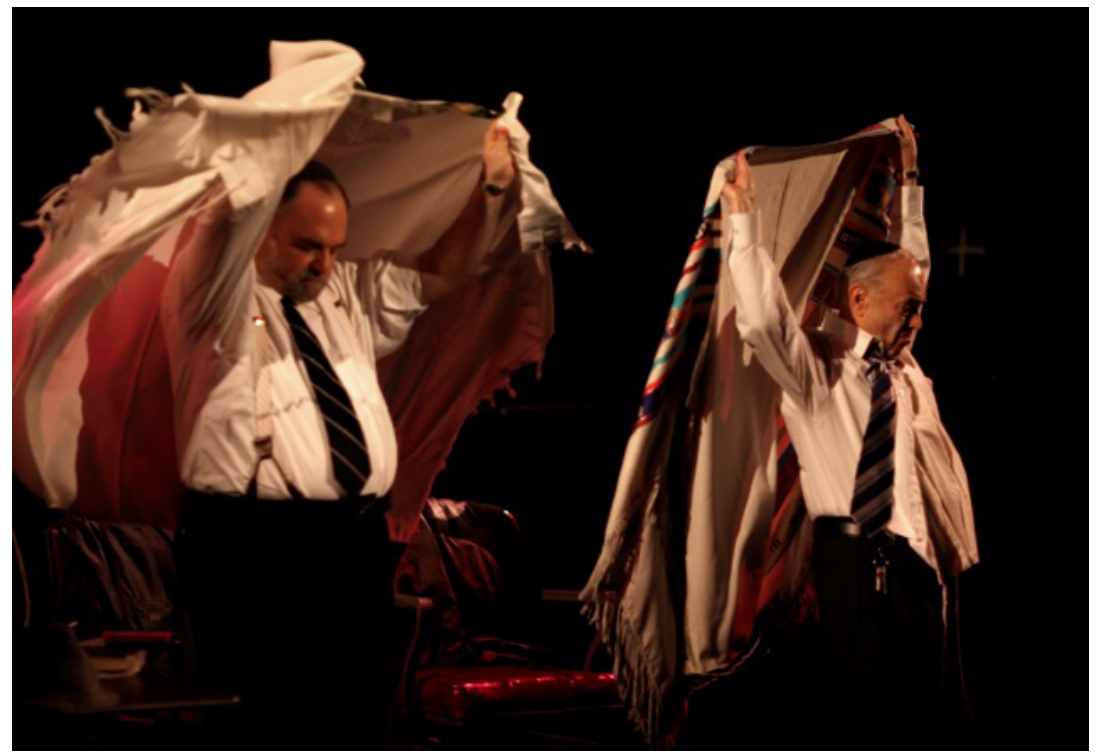

Imagen 2 - Moses Birnbaum y Hyman Levine, Rabbi Rabino, 2011, dirección de Vivi Tellas, Nueva York, Estados Unidos. Fotografía: Pascal Perich. 
Volviendo sobre el título del trabajo, me interesará entonces recorrer aquí algunos enfoques que permitan comprender en qué planos se juega la que considero la apuesta más fuerte del teatro documental según lo entiende Vivi Tellas: la de escenificar una mirada alrededor, una actitud de contemplar y actuar, y la de convocar a un encuentro entre cuerpos para que presten su testimonio, haciendo un rescate humano, una llamada de atención sobre la vida de unas personas que son como las otras personas. Creo que las obras de Archivos se convierten así en la maqueta de una sociedad mejor, en un modelo a escala, en un intento utópico, en una propuesta de encuentro entre humanos que se reconocen en su humanidad.

\section{“Yo soy...": acerca de lo testimonial}

Como decía al comienzo, Tellas ha presentado siempre a este proyecto como una experiencia de teatro documental y, en el tiempo que lleva de existencia, se ha convertido en una referencia crucial para pensar qué se entiende hoy por este tipo de teatro. Detengámonos entonces, para comenzar, en una definición posible del teatro documental. Cito a continuación una definición general como punto provisorio de consenso:

[Se trata de] obras caracterizadas por apoyarse central o exclusivamente en acontecimientos reales antes que imaginarios y en diálogos, canciones y/o materiales visuales (fotografías, films, documentos pictóricos) 'encontrados' en el registro histórico o reunidos por el dramaturgo/investigador, y por una predisposición a ubicar el comportamiento individual en un contexto político y/o social articulado (Favorini, 1995, p. XX).

Por su generalidad, esta definición podría aplicarse a la mayoría de las obras que se proponen a sí mismas como documentales. Más allá de esto, en el desarrollo de mi investigación me he confrontado con la certeza de que, al igual que en el caso del documental cinematográfico, la búsqueda documental en el teatro ostenta una gran multiplicidad y casi deberíamos hablar en plural de teatros documentales. Hace un par de años, hice un intento inductivo de sistematizar algunos ejes que permitieran pensar las variantes que se manifiestan al interior del teatro documental, teniendo en cuenta tanto su forma como su contenido (si se me disculpa, una dupla con mala prensa en la actualidad). 
[P]odríamos proponer pensar, por un lado, en un teatro documental representativo, en el que a partir de documentos escritos y orales se conforma un texto dramático que es llevado a escena por actores, que se distingue de un teatro documental testimonial, en el que los propios protagonistas suben a escena a hablar de su historia. Por otro lado, estas subcategorías podrían articularse a su vez con una escala temática que se extendiera desde el polo más claramente sociopolítico (de vocación más o menos militante) al más personal e intimista. Por último, en cuanto al uso de documentos, sean estos legajos, fotos, cartas, llaveros o ropa de la infancia, también debe poder pensarse que éstos pueden o no ser objetos usados sobre el escenario, pero que lo propio del teatro documental es que sean utilizados como base para el trabajo de la obra y que esto sea puesto siempre en conocimiento del espectador (Brownell, 2009, p. 7).

Lo que más me interesa de este primer intento de definición es el modo en el que me permite ubicar al trabajo de Tellas (como lo hacía ya en ese trabajo) en la variante testimonial. Y digo que me interesa especialmente, porque, más adelante, descubrí que resulta muy productivo pensar estas experiencias testimoniales en relación con la noción de testigo según es propuesta por Giorgio Agamben (2002). En su momento, identifiqué en los intérpretes de Archivos una actitud de prestar testimonio de sus vidas y de ahí el término testimonial. Pero recién ahora puedo comprender la profundidad de las implicancias éticas y estéticas de su carácter de testigos de sí mismos, siguiendo el análisis desarrollado para la actuación por Óscar Cornago (2011).

Pero, para llegar a la cuestión del testigo, hace falta dar un rodeo por el criterio de existencia escénica que subyace en la puesta de los archivos. Podemos decir que el trabajo reciente de Vivi Tellas está ligado a una tendencia que, desde hace unos años, se ha identificado como un teatro de lo real. El trabajo de investigación que vengo llevando adelante hace algunos años está destinado justamente a indagar qué quiere decir y a qué se aplicaría esa denominación. Lo llamativo es que quienes se proponen encarar caminos estéticos de acercamiento a lo real - o, en términos generales, a algo del mundo circundante extra teatral - suelen compartir la premisa básica de que la realidad como tal es inaccesible. Es decir que aquello real que desean incorporar, anexar a sus trabajos, no es pensado como algo cognoscible, de fronteras claras, algo asible de algún modo. Sin embargo, sí hay una intención común de avanzar hacia ese ideal, aún cuando se sabe 
que no se lo podrá alcanzar totalmente. Es por esto que me parece conveniente pensar esta búsqueda en términos de utopía. Sabiendo que la realización completa del ideal es imposible, el interés está puesto en aquello que se logrará en ese camino.

Cuando era directora artística del Teatro Sarmiento de Buenos Aires, Tellas dio inicio a su macro-proyecto Biodrama con un ciclo en el que convocaba a otros directores y dra maturgos a construir una obra a partir de la vida de una persona viva. Al presentar este ciclo que se desarrolló entre 2002 y 2008 y en el que se presentaron catorce espectáculos -, ella se refería a su interés por lo real de este modo:

Biodrama se inscribe en torno a lo que se podría llamar el 'retorno de lo real' en el campo de la representación. Después de casi dos décadas de simulaciones y simulacros, lo que vuelve - en parte como oposición, en parte como reverso - es la idea de que todavía hay experiencia, y de que el arte debe inventar alguna forma nueva de entrar en relación con ella (Tellas, 2002, s/p).

$\mathrm{El}$ arte debe, sostiene. O sea que hay una misión por cumplir, una responsabilidad. No todo se acaba al comprobar que la realidad es una construcción. Si es cierto que se terminó la historia, algo bastante parecido a ella volvió a comenzar. Lo cierto es que, como humanidad, seguimos aquí. Siguen pasando cosas a nuestro alrededor. Debemos - cuanto menos - mirarlas.

Nos ubicamos aquí en el centro de la discusión sobre la representación teatral, que supo incluir una contraposición con la noción de presentación. Si bien no quiero detenerme en esta cuestión en particular, cabe hacer algunas referencias a la propuesta de Archivos en este sentido.

A diferencia de un tipo de teatro documental que en el mundo anglosajón se identifica como verbatim - es decir, de cita textual, "palabra por palabra" (Hammond; Steward, 2008) - en el que el documentalista entrevista a los protagonistas y, luego, a partir de eso, elabora un texto que es llevado a escena por actores, Archivos propone que los que estén en escena sean los protagonistas, con sus cuerpos, sus ropas, sus tesoros.

Detengámonos en una secuencia de Mujeres Guía. Luego de discutir sobre Medea como si se tratara de una novela de la tarde mientras ingresa el público a la sala y de bailar, lentamente, al compás de Garota de Ipanema, para calentar la pista, se escuchan las primeras palabras dirigidas al público: 
Yo soy Silvana Bondanza, soy guía del Jardín Botánico de la Ciudad de Buenos Aires Carlos Thais. Yo soy Micaela Pereira, soy guía del Museo Etnográfico de la UBA. Yo soy María Irma Cavanna, soy guía-intérprete de la Ciudad de Buenos Aires.

Así se presentan, a su turno, cada una de las intérpretes. Y este "Yo soy" es fundamental, porque marca el tono de toda la obra. Lo cierto es que ellas son Silvana, Micaela y María Irma tanto como puede cualquiera ser quien es y sus nombres están tan ligados a sus cuerpos como puede estarlo el de cualquiera al suyo (un mundo de discusiones filosóficas y la perspectiva del mismo Agamben complejizan esta afirmación aparentemente tan simple). Aunque pueda aceptarse que toda persona en escena (al igual que en cámara) se transforma ya en un ente poético distinto de sí mismo, aún si habla en nombre propio, tampoco puede obviarse el hecho de que ellas siguen siendo Silvana, Micaela y María Irma cuando termina la función. Y esto cambia todo (aunque a la vez no cambie nada, porque hay tanta construcción poética como en cualquier otro caso).

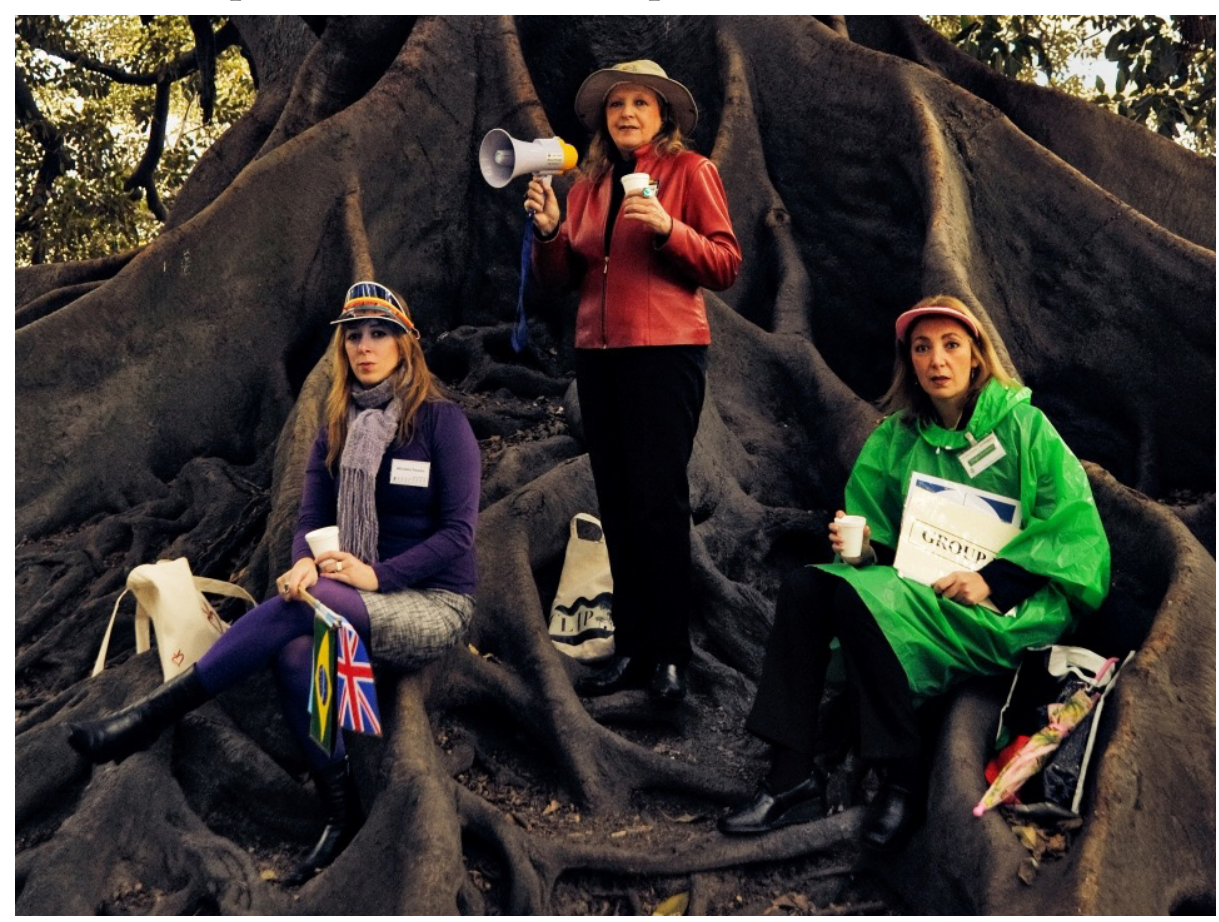

Imagen 3 - Micaela Pereira, María Irma Cavanna y Silvana Bondanza, Mujeres Guía, 2011, dirección de Vivi Tellas, Buenos Aires, Argentina, Imagen de difusión del reestreno. Fotografía: Nicolás Goldberg.

Lo que vale la pena destacar, en relación a esto, es que la presencia de los propios intérpretes en Archivos no parte de un fetichismo de las personas reales, de una idea espectacularizante de poder ver a estas celebrities cotidianas. Entiendo que esta elección de forzar los 
límites de la escena, encarando un proyecto destinado a trabajar con no-actores, como se los suele llamar en el campo del cine, significa una respuesta posible a esa imposibilidad seguida de utopía (a esa nostalgia) de lo real. Las guías no serán la realidad personificada, pero al menos puede decirse que son as real as it gets.

En este sentido avanza la distinción que realiza Philippe Dubois al hablar de la imagen fotográfica en su reflexión sobre el documental audiovisual:

Se ve claramente que se ha pasado de un efecto de realismo (que tiene que ver con la estética de la mímesis) a un efecto de realidad (que surge, a su vez, de una fenomenología de lo Real). Si el primero presenta sus conceptos en términos de semejanza, el segundo lo hace en términos de existencia y de esencia (Dubois, 2001, p. 20).

En la exhibición de los distintos documentos a lo largo de la obra también está presente esta lógica de la existencia: los aros regalados por la turista asiática, el dibujo de la hija, el disco clandestino con la Cantata Montonera que fue escondido por los padres entre unas chapas del techo, el vestido de la noche en que conoció a su futuro marido y tantos otros son rastros de una experiencia vivida y, a modo de fragmentos de una vasija desempolvada por un arqueólogo, portan con ellos un mundo, una cadena de prácticas, con las que mantuvieron una relación de contigüidad. Los objetos, a su vez, también son testigos. Testigos mudos, pero, en cierto modo, testigos también, porque han sobrevivido al fluir de la vida para llegar a ser mostrados ahí y a contar su historia en un lenguaje sin palabras.

El testigo. Ahora sí. Agamben dedica su texto Lo que queda de Auschwitz principalmente a la figura del testigo y, en particular, a su posibilidad de dar cuenta de aquello que ocurrió en los campos de concentración del nazismo. En distintos momentos se refiere a la etimología del término, cuyos diversos orígenes arrojan luz sobre su sentido profundo. Al dedicarse al último de esos orígenes, sintetiza el recorrido de esta manera:

Si testis hace referencia al testigo en cuanto interviene como tercero en un litigio entre dos sujetos, y superstes es el que ha vivido hasta el final una experiencia y, en tanto que ha sobrevivido, puede pues referírsela a otros, auctor indica al testigo en cuanto su testimonio presupone siempre algo hecho, cosa o palabra - que le preexiste y cuya fuerza y realidad deben ser confirmadas y certificadas (Agamben, 2002, p. 156). 
El testigo es, entonces, el sobreviviente de una experiencia preexistente que se requiere confirmar y puede dar cuenta de ella, en cierta medida, ante terceros. Pero el problema es que aquella experiencia - en este caso del exterminio - sólo fue conocida en su plenitud por quienes lo padecieron hasta sus últimas consecuencias. Quienes sobrevivieron no fueron exterminados. El nudo de su planteo, o al menos de su punto de partida teórico, está comprendido en esta frase: "[...] los supervivientes daban testimonio de algo que no podía ser testimoniado" (Agamben, 2002, p. 10). Pero es justamente esta imposibilidad la que los habilita para el testimonio. El testigo integral, el testigo perfecto, está muerto. No puede dar testimonio. El no serlo habilita al sobreviviente a hablar por los que no pueden hacerlo.

De esta reflexión particular, Agamben extrae consecuencias lingüísticas, filosóficas que no conciernen solamente a los sobrevivientes de los campos, sino que pueden extenderse a todo testimonio (es decir, a todo acto de habla de un sujeto ante otro), ya que aquello que realmente se querría decir, no puede jamás ser dicho. En los términos del presente trabajo, aquella realidad que se quiere abordar, invitar, relatar, poner en escena, no puede ser alcanzada, es un imposible. Sin embargo, es sobre esta imposibilidad que se afirma la palabra. El silencio es sólo una comunión con lo imposible. El decir aún cuando no se puede decir es un gesto afirmativo de enorme potencia, que porta consigo - como mínimo - el sentido de su propia afirmación como posibilidad.

Cornago parte del desarrollo teórico de Agamben y lo traslada al campo teatral para pensar la potencia de los actores que se exponen en su materialidad, en su humanidad, frente a un público que puede leer en ellos lo que dicen aún sin hablar. Aquello que portan sus cuerpos. Aquellos rastros de una existencia que pueden hablar casi de lo que no puede ser dicho.

Necesitamos que el testigo pueda hablar para que dé testimonio de lo que presenció, de lo que pasó y le pasó. Sin embargo, el testigo es en primer lugar un cuerpo-confesión, lo que nos interesa es su pura presencia, el relato de vida escrito en su cuerpo, las marcas que ese pasado dejó en él. Lo queremos ver a él, verlo de cerca, llegar a tocarlo tal vez. Incluso si no es capaz de hablar con fluidez, si su memoria ya no le permite hilvanar el relato de lo que sucedió, queda su cuerpo como testimonio mudo, la base que garantiza la verdad de su palabra (Cornago, 2011, p. 25). 
Como explica, "cuerpo y palabra [...] son las dos dimensiones sobre las que articula Agamben el lugar del testigo; la primera se relaciona con el ser viviente, que remite a su comportamiento biológico, y la segunda con el ser hablante, sobre la que se construye su condición social" (Cornago, 2011, p. 25). Archivos se apoya en ambas. Interesa escuchar el relato de estas mujeres, en el caso de las Mujeres guía, no sólo por lo que cuentan, sino por su modo de contarlo, por las marcas de su condición social que portan en su palabra. E interesa también que esta palabra se apoye en sus cuerpos y en su voz (elemento articulador fundamental entre ambas dimensiones). Lo que se ve en escena es, desde esta perspectiva, un cuerpo-confesión, que habla más allá de la voluntad de cada intérprete.

Hay otro elemento central que Cornago señala para el testigo y está presente en la definición etimológica de Agamben: el lugar del otro, el que mira, el que escucha. Hablando del teatro de Federico León, Cornago señala que

[...] el hecho de hacerse público, la mirada del otro, es el elemento desencadenante de ese mecanismo cuya finalidad es expresar emociones que habitan en el cuerpo pero no son fácilmente expresables, convertir el cuerpo en testigo de sí mismo y a pesar de sí mismo (Cornago, 2011, p. 13).

Esto se articula con su definición de la actuación como "[...] lo que se hace motivado por la presencia del otro" (Cornago, 2011, p. 13).

En el caso de Archivos, este otro es doble. Quien habilita el testimonio es, en primer lugar, la directora, Tellas. Éste es - entiendo - su gran gesto político. Ella mira y escucha y sus obras señalan - con su sola existencia - esa mirada y esa escucha. Por eso, hablo en este trabajo de la escenificación de una mirada. De una mirada y de una escucha, cabría decir. Jean-Louis Comolli plantea algo respecto del trabajo con personas reales en la realización documental que puede servir para pensar este punto: "El simple hecho de escucharlos aparece al final como un mínimo enorme, porque hoy no es para nada acostumbrado" (Comolli, 2007, p. 68).

Pero Tellas no sólo mira y escucha, sino que elige, ordena, suma, crea, monta, pone en escena. Así se complejiza la idea de confesión, al menos en el nivel de la palabra. Confieso lo que otro me ha pedido que confiese ${ }^{2}$. Pero la confesión del cuerpo, ésa sí excede a toda voluntad.

El segundo otro que habilita el testimonio es el público. Es sólo su presencia la que le da sentido y lo hace posible función tras función. 


\section{Para Muestra Basta una Vida}

En la declaración de intenciones de Biodrama que antes citaba, Tellas planteaba que el arte debe encontrar nuevos caminos para seguir haciendo algo con la experiencia. Entiendo que el camino elegido por ella para hacerlo tiene que ver con dirigir la mirada desde el teatro a las vidas humanas. ¿Pero cómo se lleva a la práctica un objetivo tan amplio?

Bueno, una alternativa, una estrategia posible, es mostrar algunas vidas humanas y esperar que el gesto tenga una potencia multiplicadora. Estaría funcionando aquí la lógica del muestreo: selecciono algunos casos particulares que considero representativos - se trataría de una muestra no probabilistica intencional (Padua, 1993, p. 87) - y de la información que recibo de ellos extraigo conclusiones para un universo mayor.

Aunque pueda ser un poco extremo llevarlo a este plano, lo que busco señalar es que, contrariamente a Aristóteles, los Archivos no prefieren lo que podría ocurrir (lo verosímil), sino que prefieren lo que efectivamente ha ocurrido (aún cuando resulta frecuentemente inverosímil). Paradójicamente, es este procedimiento el que favorece la identificación del público con las historias puestas en escena. No porque se refieren a cosas que le podrían pasar a cualquiera, sino porque se refieren a cosas que efectivamente le han pasado a esos cuerpos confesionales que son las intérpretes. Y las vidas de todos están plagadas de inverosimilitudes como aquellas. Y entonces de ahí surge una nueva idea de lo verosímil: porque le ocurrió a ella que es una persona de a pie como yo (no un personaje imaginario, no un gran héroe de la historia), me podría pasar a mí. Además, es cierto también que los seres humanos compartimos muchas experiencias y que aquello que creemos único y original en cada una de nuestras vidas se revela, tras un rato de charla, como algo que otro ha vivido también tal cual. Esta relación entre confesión, intimidad, exhibición de documentos e identificación me resultó particularmente bien sintetizada en algo que me dijo un espectador tras asistir a una función de Mujeres Guía: Todos tenemos esa foto.

Y del mismo modo que todos tenemos esa foto o ese vestido o esa anécdota (o la podríamos tener), todos compartimos cierta lógica de funcionamiento en nuestra cotidianeidad. Quiero decir, todos compartimos el hecho de diseñar/padecer una lógica de funciona- 
miento en nuestra cotidianeidad, aún cuando éstas sean distintas. Y aquí me resultan más que pertinentes las reflexiones de Michel de Certeau (1980), quien da cuenta de una verdadera microfísica de la resistencia (no usa este término, pero se desprende de su planteo) que es, a la vez, análoga y contraria a la microfísica del poder de Foucault. Mientras ésta da cuenta de la infiltración de los dispositivos de control en las instituciones y las prácticas de los sujetos, la otra llama la atención sobre los modos en los que los sujetos inventan su cotidianeidad, resistiendo esa infiltración con sutiles actos creativos que impregnan sus vidas. Así, al presentar su libro explica que buscará "exhumar las formas subrepticias que adquiere la creatividad dispersa, táctica y artesanal de grupos o individuos atrapados en lo sucesivo dentro de las redes de la 'vigilancia'” (De Certau, 1980, p. XLV). El autor parte de la idea de que debe haber una lógica de estas maneras de hacer cotidianas y por eso habla de artes de hacer. Esta afirmación se conecta con las preguntas que se hace Comolli respecto de la realización documental que busca retratar a las personas comunes:

¿Qué es entonces filmar y hacer actuar a alguien que no tiene ni la profesión ni la especialidad, alguien que está allí para otra cosa, con otros asuntos, otra lógica, otra realidad? ¿Qué es la auto-puesta en escena de los hombres comunes? (Comolli, 2007, p. 79).

Tellas busca, con sus Archivos, hacer arte con esas artes, poner en contacto la lógica de la escena con esas otras lógicas y ver qué sucede. Su expectativa es de ida y vuelta: espera que ese contacto modifique la realidad (de estas personas, al menos; ojalá, también del público) y también que este influjo de realidad modifique al teatro. Ésta es la doble dirección de su apuesta estético-política.

La familia que elige cantar la marcha peronista en lugar del feliz cumpleaños, las técnicas de seducción de un playboy, las técnicas de seducción $a$ un playboy, las formas de encarar la maternidad, los movimientos de baile, los viajes, las elecciones laborales, la disposición a jugar al teatro en una puesta en escena final de Medea, la imposibilidad de contener la emoción al hablar de un momento difícil como el de rozar la locura o extrañar a la madre que ha muerto... Todas éstas son pequeñas evidencias, pequeñas muestras, de la creatividad cotidiana de estas mujeres, que funcionan como muestra de las que podrían ser las nuestras. Alguien ha mirado a estas mujeres y ha decidido que sus historias, sus lógicas, sus artes de hacer son dignas de exposición, de ser vistas y escuchadas. Éste es el mensaje 
(pensado como una consigna general y no como un sentido cerrado) que podríamos inferir a partir de ésta y las demás obras de Archivos.

\section{Documentar lo Indocumentable: la dialéctica semejanza/diferencia}

¿Qué diferencia a Mujeres guía de una entrevista pública? ¿Qué convierte a estos confesionarios en obras teatrales? Quien haya visto las obras notará rápidamente el carácter puramente retórico (o tal vez deba decir, teórico) de estas preguntas, puesto que en ningún momento podríamos decir que los Archivos se instalen como algo distinto del teatro. Es un teatro distinto, sí, pero siempre teatro. ¿Pero cómo es concretamente que se logra esto, cuando se parte de las historias reales de personas reales que vienen a personalmente a compartirlas? Es decir, ¿qué tipo de escena propone el teatro documental de Vivi Tellas? Analicemos ahora con mayor detalle el aspecto de sus procedimientos constructivos.

Para intentar reponer sucintamente algo del espectáculo para quienes lo desconozcan, retomo la sucesión de secuencias donde la dejé, tras la presentación de las tres guías. A esto le sigue la exhibición por turnos de regalos que han recibido de parte de asistentes a sus visitas guiadas. María, que trabaja con turistas extranjeros, tiene varios y son lindos y exóticos. Micaela recibió sólo un llavero y Silvana, una latita empezada de caramelos de propóleo, porque tuvo un ataque de tos, ya que es alérgica al polvo, el polen y los gatos (tres cosas hiperpresentes en el Jardín Botánico). Casi siempre, aquí se escuchan risas del público. Ellas no se ríen, vuelven a la mesa a dejar sus documentos en la mesa y adoptan las posiciones del siguiente cuadro.

El primer relato extenso es el de Silvana. Mostrando distintas fotos, telegramas, dibujos. Propone un recorrido express desde su infancia hasta la actualidad, con una parada especial en algunos ańos muy desventurados de su vida. El público, que en general comienza riéndose mientras escucha su claramente guionado relato breve al compás de los documentos mostrados, se ve sorprendido en su buena fe cuando el comienzo sutilmente jocoso desemboca en la muerte de su padre, el desempleo, el remate de su casa y una crisis emocional tras el nacimiento de su hija, de la cuál temía no poder hacerse cargo. En ese momento, Silvana generalmente se emociona y le cuesta continuar hablando con fluidez. El momento exacto del relato que detona su emoción, sin embargo, varía de función a función. Llegado ese punto, hace una pausa en el relato, poniendo fin 
a una suerte de progresión dramática, y va hacia atrás a buscar algo de abajo de la mesa, que resulta ser un enorme traje de conejo que nos remite a una simpática primera foto de un carnaval de su niñez y que, a la vez, contrasta radicalmente con el pequeño traje del retrato. El traje es enorme, de peluche, y basta con que se lo presente frente al cuerpo para que quede claro que el momento trágico ha terminado. Vuelven las sonrisas. Ahora retoma el relato sobre cómo las cosas mejoraron. El punto clave es haber conseguido el trabajo del Botánico. Entonces comienza a hacer una visita guiada, concentrándose en un árbol en particular, el Gingko Biloba. Allí solicita la ayuda de las otras intérpretes, que hacen de árboles, logrando una imagen muy divertida, que acompaña el entusiasmo que ahora tiene la voz de Silvana. Hacia el final de esa escena, ella arroja sobre las compañeras-árboles y sobre el piso supuestas hojas secas de Gingko, aludiendo a la alfombra dorada que forman en el Botánico en otoño y que todo el mundo quiere ver. Las hojas suelen engancharse en el cabello de las chicas, golpearlas en la cara, etc., generando una peculiar variedad de micro-gags azarosos. Tras unas pocas palabras más, Silvana cierra su momento diciendo "y lo más importante es que a este árbol lo llaman el árbol de la vida, porque es el único que sobrevivió a la bomba de Hiroshima". Con esas palabras aún suspendidas en el aire, Micaela, con los brazos todavía en alto simulando las ramas (que rápido devendrán el famoso gesto de Evita en el balcón) dice: "Yo vengo de una familia peronista. Militante fanática", y continúa.

Me detengo aquí porque temo ya haber abusado de la descripción. Sólo algunas viñetas sueltas del resto de la obra: María interrumpe el relato de Micaela para dar el "Evita tour"; Micaela lamenta que su madre - que de militante de base llegó a ser diputada - haya muerto y, entre otras cosas, no haya podido vivir el presente momento político de la Argentina "con Cristina en la Rosada". Hay un momento musical en el que ordenan, otro en el que bailan; luego, en la historia de María, las tres participan de una divertida recreación de su primer encuentro en un boliche de los años setenta con su actual marido, sobre el final realizan un intento de poner en escena Medea con una disfrazada de Evita y otra de conejo y, finalmente, tras el asesinato de los hijos y la coda final de unas estrofas de tango, se oye una música alegre, se invita al público a bailar y se da comienzo a la picada, en la que todos pueden comer y conversar sobre lo que hasta hace poco era el espacio escénico. 


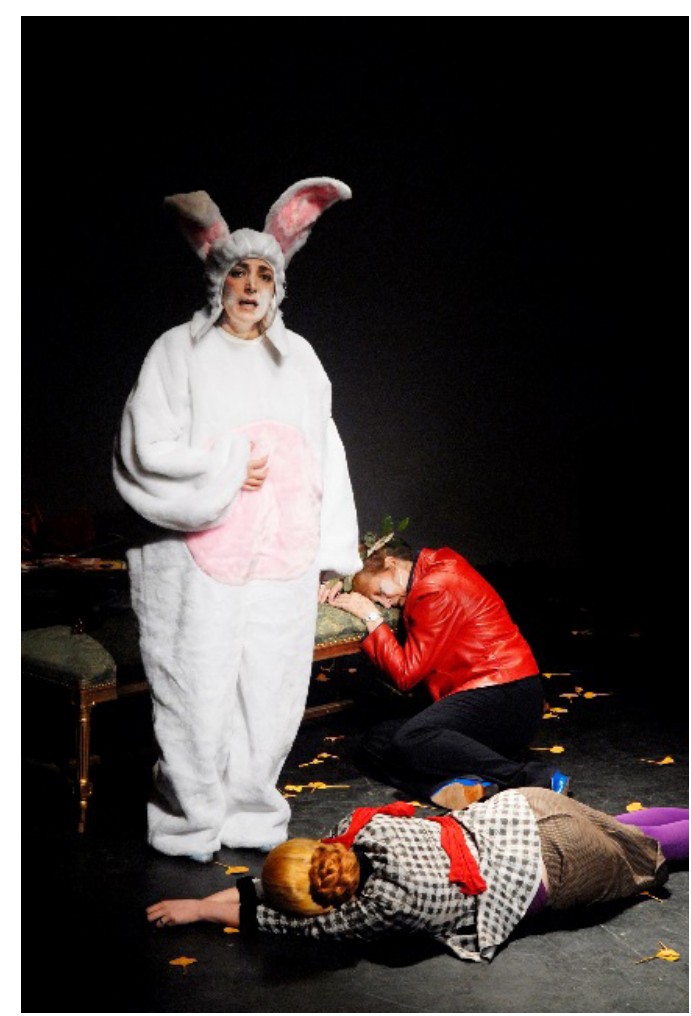

Imagen 4 - Silvana Bondanza, María Irma Cavanna y Micaela Pereira, Mujeres Guía, 2008, dirección de Vivi Tellas, Buenos Aires, Argentina. Fotografía: Nicolás Goldberg.

En este (extenso) recuento se pueden identificar algunas claves de la dinámica compositiva de la obra. En principio, una permanente tensión entre fragmentación y articulación. Desde los parlamentos hasta las escenas, pasando por los gestos, todo se evidencia como un zurcido bien ensayado de partes que logra una unidad sorprendente. En gran medida, el sutil humor de la obra está basado en esa forma de devenir, de fluir de un tema a otro, de una acción a otra, de una emoción a otra. Así, la obra parece querer condensar una vida en una hora. La obra misma se transforma en una micro-vida, con risas, llantos, baile, preocupación, historia, anécdotas, intervalos, imágenes, colores, sonidos, personas. $\mathrm{Y}$, en esta operación evidente de montaje que se señala a sí mismo permanentemente, está la clave de su ser teatro. Hay algo del afuera que es invocado constantemente, pero también hay una realidad del aquí y ahora, que se juega en clave estrictamente escénica, y un señalamiento insistente en los procedimientos artísticos operados sobre ese material real que remiten a una paradoja, que he llegado a identificar como constitutiva del teatro documental: cuanto más se exalta el componente de realidad de una propuesta, más se refuerza también el componente de artificio. 
Al respecto, Dubois hace alusión a un concepto que me resulta especialmente productivo para pensar esta aparente paradoja. En su caso, está pensando la relación entre la base tecnológica y la representación en la fotografía y el cine. Las características propias del soporte fotográfico y audiovisual muchas veces cobraron una importancia tal en la reflexión teórica que llevaron a olvidar el rol de los procedimientos de montaje como opciones estéticas. En este sentido, sostiene:

Toda representación implica siempre una 'dosificación' entre semejanza y diferencia. Y la historia estética de las máquinas de imágenes, esa trenza de líneas generales, está hecha de sutiles equilibrios entre tales datos. Hasta se puede sostener con razón que existe una suerte de correlación histórica implícita entre esas dos dimensiones, aparentemente contradictorias de la figuración. Es la tesis dicha de la 'doble hélice' sostenida por Raymond Bellour que vuelve, sumariamente, a decir que cuanto más se extiende el poder de analogía de un sistema de imágenes, más se manifiestan tendencias o efectos (¿los llamaríamos secundarios?) de des-analogización (de desfiguración) de la representación. Como si a la mayor posibilidad de un sistema de imitación de lo real en la más fiel de sus apariencias, correspondiera una mayor multiplicación de pequeñas formas que minaran ese poder de mimetismo, que trataran de deconstruirlo como una revancha de la imagen sobre el instrumentalismo de la máquina, como si tuviéramos que vernos ante una pulsión de subversión de la figura proporcional a la fuerza de dominio del sistema (Dubois, 2001, p. 23).

Los distintos dispositivos estéticos - para extender a un plano general su reflexión - eligen su propia manera de "formalizar la dialéctica entre semejanza y diferencia" (Dubois, 2001, p. 24). El teatro documental invoca continuamente esta dialéctica. ¿Es o no es? ¿Le pasó o no le pasó? Parece que sí le pasó, pero ahora está jugando a representarlo teatralmente. Lo que me cuenta, ¿es igual a lo que me contaría si no estuviera en una obra de teatro? Cada una de las mujeres guía, como decíamos antes, es una mujer guía. $\mathrm{O}$, mejor dicho, es una mujer que en una de las esferas de su vida trabaja de guía. De alguna forma, el ser-mujer-guía en tanto parte de este espectáculo es su personaje.

La escenificación de esta dialéctica, la generación de esas tensiones, el señalamiento de la mirada y del montaje, el poner al cuerpo-testigo a hacer de Medea, constituyen para mí las bases de la potencia de esta propuesta. 


\section{Palabras Finales}

En el programa de mano de varias obras del ciclo Biodrama solía leerse un breve texto de Tellas que incluía esta pregunta: "En un mundo descartable, ¿qué valor tienen nuestras vidas, nuestras experiencias, nuestro tiempo?”.

Vuelvo entonces sobre las palabras de Matta y su idea de que el artista debe "dar a ver". El artista debe crear las condiciones para que "nos miremos los unos a los otros", para que entendamos que debemos realizarnos como seres humanos.

Creo que la revalorización de las vidas humanas que propone Tellas a partir de su mirada puesta en acto y del encuentro que busca generar en Archivos - podría decir, su humanismo artístico - se inscribe en este deseo de dar a ver y constituye un ejemplo valioso de intervención artística en los debates centrales de la sociedad de nuestro tiempo. 


\section{Notas}

${ }^{1}$ Texto impreso a la entrada de la exposición dedicada al artista chileno Roberto Matta: Matta100, Museo Nacional de Bellas Artes de Santiago de Chile, del 9 de noviembre de 2011 al 4 de marzo de 2012.

${ }^{2}$ El proceso de dramaturgia de estas obras es sumamente interesante y resulta de un largo proceso de intercambios, negociaciones, creaciones conjuntas y confesiones mutuas que, lamentablemente, no podemos abordar aquí.

\section{Referencias}

AGAMBEN, Giorgio. Lo que queda de Auschwitz: El archivo y el testigo. Homo sacer III. Valencia: Pre-Textos, 2002.

BROWNELL, Pamela. Investigaciones, Archivos y Expedientes: una reflexión sobre el concepto de teatro documental a partir de un recorrido por algunos casos paradigmáticos de la escena local internacional. In: IV CONGRESO INTERNACIONAL ARGENTINO DE TEATRO COMPARADO, nov. 2009, Tandil. Ponencia (actas en prensa).

COMOLLI, Jean-Louis. Ver y Poder: la inocencia perdida: cine, televisión, ficción, documental. Buenos Aires: Aurelia Rivera-Nueva Librería, 2007.

CORNAGO, Óscar. Actuar "de verdad". El actor como testigo de sí mismo. DDT - Documentos de Danza y Teatro, Barcelona, Teatre Lliure, n. 18, p. 23-41, 2011.

DE CERTEAU, Michel. La Invención de lo Cotidiano I: artes de hacer. México: Universidad Iberoamericana, 1980.

DUBOIS, Philippe. Cine, Vídeo, Godard. Buenos Aires: Libros del Rojas/Universidad de Buenos Aires, 2001.

FAVORINI, Attilio. Introduction. After the Fact: Theater and the Documentary Impulse. In: FAVORINI, Attilio (Org.). Voicings. Ten Plays of Documentary Theater. Nueva Jersey: The Ecco Press, 1995.

HAMMOND, Will; STEWARD, Dan (Org.). Verbatim Verbatim. Contemporary Documentary Theatre. Londres: Oberon Books, 2008.

PADUA, Jorge et al. Técnicas de Investigación Aplicadas a las Ciencias Sociales. México: FCE, 1993.

TELLAS, Vivi. Comienza el Biodrama. Buenos Aires: Complejo Teatral de Buenos Aires, 9 abr. 2002. Gacetilla de prensa.

Pamela Brownell es licenciada en Artes y en Periodismo. Es doctoranda de la Universidad de Buenos Aires y becaria del Consejo Nacional de Investigaciones Científicas y Técnicas. Es docente e investigadora de la Facultad de Filosofía y Letras de la Universidad de Buenos Aires, cátedra de Análisis y crítica del hecho teatral. También participa del área de Políticas Culturales del Centro Cultural de la Cooperación.

E-mail: pamela_brownell@yahoo.com.ar 